\title{
Unusual presentation of triple A syndrome mimicking Sjögren's syndrome
}

\author{
Ahmet Mesut Onat • Yavuz Pehlivan • \\ Hakan Buyukhatipoglu • Yusuf Ziya Igci • \\ Seydi Okumus $\cdot$ Cemile Arikan • Sibel Oguzkan
}

Published online: 10 February 2007

(C) Clinical Rheumatology 2007

\section{Clin Rheumatol DOI: 10.1007/s10067-006-0498-5}

The surname of the fourth author was inadvertently omitted.

The author's full name is Yusuf Ziya Igci.

The online version of the original article can be found under doi:10.1007/s10067-006-0498-5.

\footnotetext{
A. M. Onat

Department of Rheumatology,

Gaziantep University School of Medicine,

Gaziantep, Turkey

Y. Pehlivan $\cdot$ H. Buyukhatipoglu $(\varangle) \cdot$ C. Arikan

Department of Internal Medicine,

Gaziantep University School of Medicine,

Gaziantep, Turkey

e-mail: buyukhatip@yahoo.com

Y. Z. Igci · S. Oguzkan

Department of Medical Biology and Genetics,

Gaziantep University School of Medicine,

Gaziantep, Turkey

\section{S. Okumus}

Department of Ophthalmology,

Gaziantep University School of Medicine,

Gaziantep, Turkey
} 